\title{
DISCUSSION
}

\section{HOW DIGITAL TRENDS ARE CHANGING THE MARKETING LANDSCAPE}

Although we are not yet fully exposed to the impact of new technology, we are increasingly forced to adapt to changes in the digital sphere. As already about three billion people on Earth have on-line access (Business Insider, 2013), we have moved from an informationhungry to an information-overloaded society; we are addicted to new technology and social media.

We live in turbulent times. We see tremendous changes in marketing, which has already shifted from the mass communication model - when marketers used to tell consumers what was best for them, to more personal, mobile, social conversations based marketing which favors lasting partnerships between brands and consumers. Marketing is entering a new era. As the Millward Brown BrandZ 2013 Report clearly states, "Brands must keep up as we move among the personal, social and business aspects of our lives. Brands that force us to pause or switch devices risk losing us. The rigid B2C and $B 2 B$ designations don't fully apply anymore. To move smoothly, brands can't be defined by a narrow function. Brands need to assume a higher purpose; then we grant them permission to be present all the time" (Millward Brown, 2013).

Marketing budgets have to reflect on this changing consumer behavior. There is no more discussion about if money should be allocated into digital activities - the only questions remaining are what proportion of the budget should stay off-line and how to best integrate both worlds; how to create a relevant buzz for a brand in the digital sphere, as digital disruption is not just about easy access to information, but also about the new consumer's experience and entertainment.

The presence of social media is also becoming more sophisticated over time. Marketing experts all over the world have already learnt from their digital failures and experiments, and they are starting to exploit competitive advantages for their brands in social media, mobile, content, and video. Marketers are moving their priorities from fan/followers' quantity to quality and increasingly driving the engagement of targeted, passionate, and influential brand ambassadors. Brands are continuously growing sales directly attributed to digital marketing campaigns (conversion rates).

Nevertheless, the next big challenge for the marketing community will be learning how to exploit the disruptive trends coming from smart shopping, big data, cloud, and clever digital devices (Internet of Things and eventually Internet of Everything), that are expected to explode in the mid-term future.

\section{Behavior-Based Data Decisions}

The strategic approach to technology, big data, and cloud services, linked with the introduction of location based services, is expected to be the next "big thing" as it will enable progressive companies to lead the digital 'game'. At present, the priority is mainly being centered around the collection, measurement and usage of behavior-based data that will drive new ways of consumer segmentation, addressing new deeper consumer insights, which will result in the smarter, and thus more effective, allocation of marketing investments, more individualized communication, and the creation of more personal experiences.

The cleanness and the quality of a companies' data and their leveraging from multiple channels and sources, their storage and automated processing in the cloud sphere, and their instant accessibility, will remain a key challenge for marketers this year, in addition to the integration of on-line and off-line activities, and the excellence of their execution.

\section{The Integration of Multiple Formats, Multiple Screens, and Multiple Channels}

Digital marketing strategies will increasingly focus on giving a spark to brands via using multiple formats (video, micro video, blogs, white papers, studies, articles, webinars, e-books, live presentations, e-mail newsletter, etc.) and multiple screens (PC vs. tablet vs. mobile), blending them with newer digital marketing channels. 
The priority will be given also to Google + , Tumblr, Instagram and Pinterest, in addition to Facebook, Twitter, and to LinkedIn in B2B.

\section{Content "Remains the King", Increasingly Shifting To Context, Shorter Formats, And Video}

As marketers continue to integrate their social media activities with their entire content strategy, they thrive to increase content attractiveness, either by involving key influencers in their marketing content creation and/or also thanks to new micro video formats.

It is expected that thanks to the young target group preference of short viral videos and picture sharing, micro-video applications from Twitter Vine (6 sec), Instagram (15 sec), MIxBit (16 sec) and Tumblr GIFs will boom. Coca-Cola, Oreo and RedBull have already pioneered this way.

\section{Mobile, the Most Disruptive Media}

The creation of content that is easily consumed in a mobile environment will become a necessity, as mobile currently accounts for one fifth of the traffic on the Internet, and is expected to surpass desktop in two years (Business Insider, 2013a). The route to success will lead via user-friendly responsive designs (both for content and for ads), via more actionable and shorter blogs and location based content marketing, enabled by GPS technology.

The mobile usage trends, originating from the U.S., will spread out to the whole world and evolve. According to RKG and Business Insider Intelligence (Business Insider, $2013 b$ ), the majority of e-mail, social media (Facebook $65 \%$, Twitter $80 \%$ ), music (Pandora $85 \%$ ), and about one third of all organic searches in the U.S. are already now consumed via mobile.

Progressive companies will reflect on their users' mobility - they will shift more investments into mobile advertising, they will set up business models for easy data availability for mobile employees and for m-commerce, that will in 2014, according to eMarketer. com (eMarketer, 2013) account for more than 19\% of Internet sales in the U.S. (in Europe even 24\%), and the percentages will continue to grow quickly.

\section{In-house Content Production}

To create more individual brand relationships, companies will start to reduce cooperation with agencies for content creation and either involve consumers in co-creating content (e.g. Airbnb), products, and sharing ideas, or they will use their own in-house newsrooms and production studios, as we already see from pioneers in this field Netflix (House of Cards), Red Bull (Media House) and Amazon (Alpha House).

\section{Digital Literacy}

As digitalization will progress, social media and technological literacy will become a must-have skill for most jobs, not just in marketing. Professionals will be required to master content development and its curation, information search, and aggregation of multiple data points for decision making in real time. The digital landscape will become an even more inseparable part of our professional and personal lives.

\section{Progress Cannot Be Escaped}

Major changes in the digital sphere are around the corner, and only those companies and brands, which are able to find and build their unique digital "footprints" and "meaningfully different" brand experiences, that will be flexible and fast enough to adopt their business models, strategies and plans to these changes, will be the ones, who are able to remain relevant for the years to come.

\section{References}

Business Insider (2013). Business Insider (BI Intelligence): International Communication Union, Google, 2013.

Millward Brown (2013). Millward Brown BrandZ 2013 Top 100 Report, May 2013, [available at: http://www.millwardbrown. com/brandz/Top_100_Global_Brands.aspx].

Business Insider (2013a). Business Insider (BI Intelligence): StatCounter, September 2013.

Business Insider (2013b). Business Insider (BI Intelligence): Source Mary Meeker, Kleiner Perkins, Companies, BII estimates, RKG, 2013.

eMarketer (2013). eMarketer.com; Dec 9, 2013: Key Trends for 2014: Always-On Commerce, [available at: http:// www.emarketer.com/Article/Key-Trends-2014-AlwaysOn-Commerce/1010439\#wSSZuThBqQ7GL4Po.99]. 